\title{
Research and Practice of Information Technology Teaching in Junior High School Based on Micro-Lesson
}

\author{
Yingxin $\mathrm{Liu}^{1, *}$, Jingrui $\mathrm{Li}^{1}$, Baoyu $\mathrm{Niu}^{1}$, Liang $\mathrm{Shi}^{1}{ }^{1}$ Lu Tian ${ }^{2}$
}

\author{
${ }^{1}$ Shenyang University, Shenyang, Liaoning 110044, China \\ ${ }^{2}$ Shenyang Education Research Institute, Shenyang, Liaoning 110083, China \\ *Corresponding author. Email: yingxin888@126.com
}

\begin{abstract}
Micro-lesson, as an emerging digital learning resource, has a great impact on traditional teaching, and also makes up for the shortcomings of traditional teaching methods and modes. The study applied micro-lessons to the teaching of secondary school Information Technology course. The experimental class used micro-lessons for teaching, and the control class used traditional teaching. After the implementation of teaching, students in both classes were surveyed in the form of questionnaires, and the results of the survey were analyzed using SPSS software. The analysis showed that teaching based on micro-lesson is conducive to improving students' learning attitudes and independent learning ability, and better enhancing the effectiveness of classroom teaching.
\end{abstract}

Keywords: Micro-lesson, information technology, junior high school

\section{INTRODUCTION}

In the twenty-first century, human society has fully entered the information age. Information technology has penetrated into all fields, and people's life, learning and work have been greatly changed. In 2018, “ Action Plan for Education Informatization 2.0" states that it will continue to promote deep integration of information technology and education, comprehensively improve information literacy of teachers and students, promote the expansion from technology application to competence quality, and the application ability of information technology to solve problems in teaching, learning, and life becomes a necessary basic quality [1]. Therefore, we should respond to the development of the times and the requirements of the new round of curriculum reform, and enhance learning of information technology knowledge.

Micro-lesson is a new type of learning resources and learning methods, which attracts learners' attention with its short time, prominent theme and diverse dissemination. In recent years, the rapid development of micro-lessons has received widespread attention, and micro-lesson resources have become increasingly abundant. However, the application of micro-lessons to curriculum teaching, especially to secondary school information technology teaching, is still in the exploration stage. The use of microlessons is to share teaching resources and to lay the foundation for leading contemporary education reform and innovation.

\section{ANALYSIS OF LEARNING SITUATION}

\subsection{Analysis of Teaching Materials}

With the development of information technology, the main purpose of information technology is to cultivate students' interest and awareness of information technology, and let them understand and master the basic knowledge and skills of information technology. The selected textbook is Information Technology Textbook of Seventh Grade published by Shenyang Publishing House, and some contents of the textbook are information technology contents of elementary school. Although these contents seem simple and easy to understand, but in fact students can not be comfortable, also they can not stimulate the children's interest in learning information technology.

\subsection{Analysis of Learners}

During the period of junior high school, students' thinking ability is developing rapidly. In terms of emotion, junior high school students' independence and autonomy are increasing, but they are not very mature; in terms of behavior, because of their adolescence, their thinking is not too mature with poor self-control ability and strong rebellious mentality, and they are easily emotional in learning; in terms of knowledge accumulation, they already have a certain foundation of computer operation, with active thinking, strong imitation ability and certain independent learning ability, and they are full of the desire to explore new things. 


\subsection{Analysis of Teachers}

Although information technology teachers are teachers with rich teaching experience, they are capable of basic teaching work. On one hand, the technical ability level of information technology teachers needs to be improved continuously. On the other hand, they also have enough computer knowledge, and can create an information technology application environment to realize the application of micro-lessons in classroom teaching.

\section{DESIGN AND PRODUCTION OF MICRO-LESSON}

The design of micro-lessons mainly includes selecting topics, collecting materials, integrating contents and writing scripts. The selection of micro-lesson topics is indispensable for the design and research of micro-lesson scripts, and the selected topics for micro-lesson design should be clear. Micro-lesson script design refers to the design of each teaching knowledge point, such as layout, text, pictures, and language expressions of the micro lesson [2]. After analyzing students characteristics of junior high school, the script design of micro-lessons should be reasonable in layout, clear in teaching objectives, prominent in teaching focus, and clear in knowledge.

The general process of micro-lesson video production is to firstly determine the knowledge points to be recorded, the micro-lesson video script template and subject lesson; the next step is to choose the appropriate recording software tool for recording, and finally complete the steps of postediting work and teaching reflections. When selecting the production method of micro-lesson video, we should start from the actual situation and choose the appropriate production method according to the subject characteristics and lesson type [3]. After determining the production method of micro-lessons, the production and development of micro-lesson videos are carried out after selecting the appropriate development tools by combining the learning characteristics of junior high school students and the hardware conditions they have. The teaching was developed using a combination of PPT and video recording software, using presentation software to create the micro-lesson, EV recording software to record the screen, and format factory software to edit.

\section{PRACTICE OF MICRO-LESSON IN INFORMATION TECHNOLOGY TEACHING}

\subsection{Practice Process}

\subsubsection{Experimental objects}

The subjects of the experiment were the students of Class 1 Grade 7and Class 4 Grade 7 in a middle school in Shenyang. Through the preliminary survey, we understood that the number of students in both classes was 45 , and the same teachers taught the teaching contents, and the difference of students' overall computer foundation level was very small. Class 1 was used as the experimental class, and Class 4 was used as the comparative class, with traditional teaching method.

\subsubsection{Implementation plan for experimental and control classes}

Any research is based on the corresponding investigation and analysis. The researcher applied the designed microlesson teaching cases to information technology teaching in junior high school, and know about the teaching effect of micro-lesson according to the students' learning feedback, which provides a strong basis for the next research. The researcher chose new knowledge in the lesson, which is more helpful for students to focus their learning attention and make learning efficiency enhanced. The short video teaching style is up-to-date and also enables students to accept the main points of knowledge taught in the micro-lesson videos fast [4].

\subsubsection{Teaching process of the experimental class and the control class}

The experimental class adopts a teaching format based on micro-lessons, through which the teacher guides students to watch videos for independent learning, and then the teacher assists students to complete the teaching process of practice. It not only effectively exercised students' handson skills, but also enabled them to discuss problems with the teacher in a targeted manner when they conducted practical exercises in the classroom, thus effectively improving their operational skills [5]. The control class followed the teaching process in the form of traditional professors' mode of instruction and teachers' demonstration teaching. The specific teaching process is shown in Table 1. 
Table 1 Teaching process of the experimental and control classes

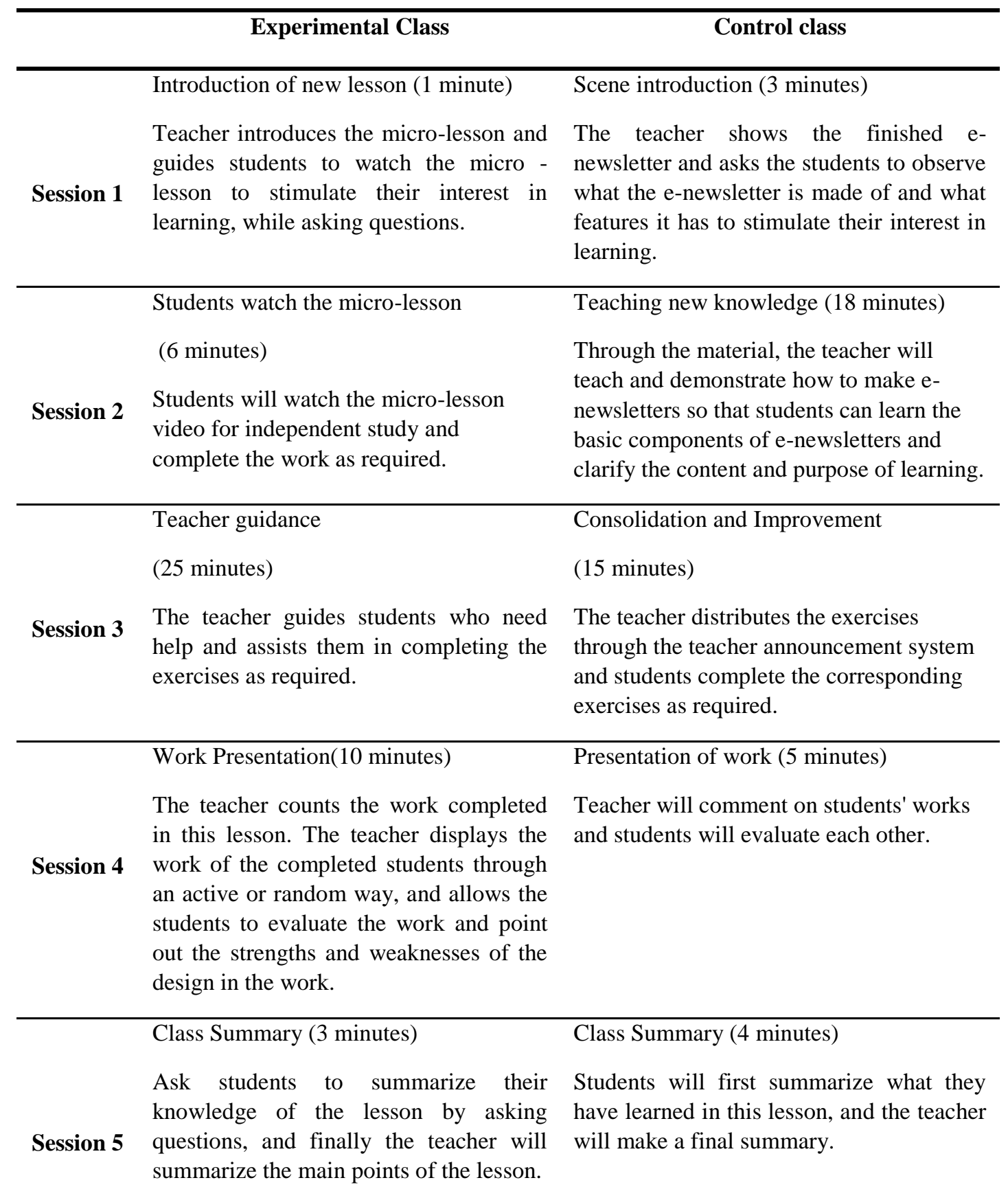

\section{ANALYSIS OF TEACHING EFFECT}

\subsection{Questionnaire Design}

Based on the "Information Technology Curriculum Guideline for Primary and Secondary Schools (for trial implementation)", through the collation and summarization of relevant literature and using the dissertation as reference, after repeated investigations and experiments, we finally compiled a questionnaire "Questionnaire on Teaching Effectiveness of Information Technology Class", which includes two dimensions of learning attitude and independent learning ability, so as to test the teaching effect of micro-lessons. The basic objectives of the questionnaire were determined first, and the questionnaire was prepared according to the objectives. Twenty questions were included in the questionnaire, with 1-10 questions testing students' self-learning ability and 11-20 questions testing students' learning attitude. The method used in the questionnaire is the Richter 5-point scale. 


\subsection{Questionnaire Analysis}

The researcher used SPSS statistical analysis software to test the reliability and validity of the questionnaire of Teaching Effectiveness of Information Technology Questionnaire, which was analyzed as follows.

\subsubsection{Reliability analysis}

Table 2 Reliability analysis
Reliability refers to consistency degree of the results obtained when the same method is used to measure the same object repeatedly [6]. For the Clonbach coefficient, if the value is greater than 0.8 , it means that the questionnaire has a very high reliability; if the test value is between 0.7-0.8, it means that the questionnaire has good reliability; if the test value is between $0.6-0.7$, it means that the reliability of the questionnaire is still acceptable; then if the test value is lower than 0.6 , it means that the questionnaire has poor reliability and no reliability. As shown in Table 2.

\begin{tabular}{cc}
\hline Cronbach Alpha & Number of items \\
\hline .868 & 20 \\
\hline
\end{tabular}

As can be seen from Table 2, the reliability test by SPSS statistical software yielded a Cronbach's alpha value of 0.868 for the questionnaire, indicating that the questionnaire has good reliability and can be used for the next step of analysis.

\subsubsection{Validity analysis}

Table $3 \mathrm{KMO}$ and bartlett sphericity test resul

\begin{tabular}{lcc}
\hline & KMO & .827 \\
\hline \multirow{3}{*}{ Bartlett's spherical test } & Approximate cardinality & 998.845 \\
& Degree of freedom & 190 \\
& Significance & .000 \\
\hline
\end{tabular}

From Table 3, we can see that the KMO value of the questionnaire is 0.827 through SPSS statistical analysis software, which means that the questionnaire is suitable for factor analysis, and the test shows that the Bartlett's sphericity is 0.000 , which is much less than 0.05 and becomes a significant level, from which we can know that the questionnaire has good validity.

From the test results, the questionnaire has good reliability and validity, then the questionnaire can be used to investigate the teaching effectiveness of information technology classes.

\subsection{Data Analysis}

The survey was conducted in the form of an online questionnaire. The questionnaire was distributed to the students' computers via LAN in the IT class, and the students answered the questions by themselves, and then
Validity refers to the extent to which the measured results reflect the content to be examined, and the more the measurement results match the content to be examined, the higher the validity; conversely, the lower the validity [6]. Firstly, the KMO value is analyzed, which is roughly the same as the test of reliability, and if the KMO value is greater than 0.8 , the questionnaire has good validity; if it is lower than 0.6 , the validity of the questionnaire is poor. As shown in Table 3.

clicked the "Submit" button to submit the questionnaire for the researcher to organize and analyze.

The questionnaire was distributed in the form of questionnaire star. 90 questionnaires were distributed in this study, 90 questionnaires were collected, and the recovery rate was $100 \%$, after the later review, 90 questionnaires were valid, and the efficiency rate was $100 \%$.

\subsubsection{Homogeneity of variance test}

The homogeneity of variance test is a very important function in exploratory data analysis provided by the Explore command in SPSS, which tests whether the variances of the observed variables are equal at different levels of the control variables. If the variance satisfies the homogeneity of variance test, it means that there is no significant difference between their variances at different 
levels of the variables. On the contrary, if the significance levels corresponding to the statistics are less than 0.05 , the opposite conclusion is obtained. The results of the

Table 4 Variance homogeneity test of learning attitude and independent learning ability

\begin{tabular}{ccccc}
\hline & $\begin{array}{c}\text { Levene Statistical } \\
\text { quantities }\end{array}$ & df1 & df2 & Significance \\
\hline Learning Attitude & 8.185 & 1 & 88 & .055 \\
$\begin{array}{c}\text { Independent learning } \\
\text { ability }\end{array}$ & 2.317 & 1 & 88 & .132 \\
\hline
\end{tabular}

Homogeneity of variance test by SPSS statistical analysis software are shown in Table 4.
As shown in Table 4, the significant value for attitude toward learning is $0.055, \mathrm{P}>0.05$, and the $\mathrm{P}$-value for homogeneity of variance test of independent learning ability is $0.132, \mathrm{P}>0.05$ indicates that the variance is homogeneity test and the data can be analyzed using the variance and can be analyzed in the next step using the one-way variance.

\subsubsection{One-way ANOVA}

One-way ANOVA is a method of analyzing a hypothesis test on the mean of multiple (more than two) treatments, while one-way means that there is only one experimental factor in that experiment, and is used to determine the superiority or inferiority of this experimental factor for each treatment. ANOVA is used to analyze and determine whether the effect of one or more control factors on the overall sample is significantly different, and the criterion to determine whether there is a difference between two groups, then we need to see whether the significant value $\mathrm{P}$ $<0.05$, if the analysis result $\mathrm{P}<0.05$, it means that there is a difference between the two groups, and vice versa, there is no difference. The results of the one-way variance tested by SPSS statistical analysis software are shown in Table 5 .

Table 5 One-way anova of learning attitude and independent learning ability

\begin{tabular}{|c|c|c|c|c|c|c|}
\hline & & Square and & df & $\begin{array}{l}\text { Mean } \\
\text { Square }\end{array}$ & $\mathbf{F}$ & $\begin{array}{c}\text { Signific } \\
\text { ance }\end{array}$ \\
\hline \multirow{4}{*}{$\begin{array}{l}\text { Learning } \\
\text { Attitude }\end{array}$} & intergroup & 1.406 & 1 & 1.406 & 4.500 & $.037 *$ \\
\hline & $\begin{array}{l}\text { Within the } \\
\text { group }\end{array}$ & 27.500 & 88 & .313 & & \\
\hline & Total & 28.906 & 89 & & & \\
\hline & intergroup & 2.256 & 1 & 2.256 & 9.145 & $.003 * *$ \\
\hline \multirow[t]{2}{*}{$\begin{array}{c}\text { Independent } \\
\text { learning ability }\end{array}$} & $\begin{array}{l}\text { Within the } \\
\text { group }\end{array}$ & 21.712 & 88 & .247 & & \\
\hline & Total & 23.968 & 89 & & & \\
\hline
\end{tabular}

Note: $* * * \mathrm{P}<0.001 * * \mathrm{P}<0.01 * \mathrm{P}<0.05$

As can be seen from Table 5, the significant value $(\mathrm{P})$ of learning attitude is equal to $0.037, \mathrm{P}<0.05$, which indicates that there is variability between groups, i.e., there is variability in the perception of learning attitude toward information technology in different classes. The significant value $(\mathrm{P})$ of independent learning ability is equal to 0.003 , $\mathrm{P}<0.05$, which indicates that there is a difference between groups, that is, there is a difference in the cognition of independent learning ability in different classes, and the data analysis shows that students in Class 1 are more capable of independent learning in Class 4.

\subsection{Experimental Results}

From the experimental results, it can be concluded that micro-lesson has a greater impact on students' independent learning ability and learning attitude, and knowledge content is more effective, and through micro-lesson students' various questions are solved at any time, which enhances students' desire to learn new knowledge and their love for IT courses. With the implementation of micro- 
lessons in classroom teaching, students can experience the joy of successful operation and feel the importance and value of information technology in their daily lives, which enables students to engage in learning on their own and motivates them to learn.

\section{CONCLUSION}

With its "short and concise" features, micro-lessons present teaching content vividly and in a novel form. Students' attention and interest in classroom learning are increased, and classroom learning efficiency is high, which is conducive to the improvement of students' independent learning ability[7]. Thus, it can optimize the effect of classroom teaching and provide reference for the exploration and research of micro-lesson in IT classroom.

\section{ACKNOWLEDGMENT}

This work was supported by Undergraduate Teaching Reform Research Project of Higher Education in Liaoning Province.

\section{REFERENCES}

[1] Ministry of Education. Notice of the Ministry of Education on the issuance of the Action Plan for Education Informatization 2.0 [Z]. Teaching Technology [2018] No. 6, 2018-04-18.(In Chinese)

[2] Dong Xue. Research on the design and teaching application of microlearning based on contextual learning theory [D]. Northeast Normal University, 2005: 34-38. (In Chinese)

[3] Hu Ziwei. Research on the design and application of micro-lessons in junior high school information technology course teaching [D]. Wuhan: Huazhong Normal University, 2017. (In Chinese)

[4] Chen Jianping. Effective learning strategies for middle school information technology courses based on microlearning resources [J]. Computer Knowledge and Technology, 2019, 15(23):73-74+79. (In Chinese)

[5] Liu Kelley. Research on teaching design strategies of middle school information technology courses based on micro lessons [D]. Bohai University, 2017. (In Chinese)

[6] Wu Wenzheng. Research on cultivating information literacy of junior high school students based on "taskdriven" in information technology class [D]. Yanji: Yanbian University, 2015: 13-16. (In Chinese)
[7] Yu Wen, Liu Xiaoying. Research on the application of microcourse in middle school information technology teaching $[\mathrm{J}]$. China Education Informatization, 2018(08):28-30. (In Chinese) 